University of Nebraska - Lincoln

DigitalCommons@University of Nebraska - Lincoln

USDA National Wildlife Research Center - Staff Publications
U.S. Department of Agriculture: Animal and Plant Health Inspection Service

May 2020

\title{
Time allocation to resources by three species of rats (Rattus spp.) in a radial arm maze
}

\author{
Gary Witmer \\ USDA/APHIS Wildlife Services National Wildlife Research Center, gary.w.witmer@usda.gov \\ Nathan P. Snow \\ USDA/APHIS Wildlife Services National Wildlife Research Center \\ Rachael S. Moulton \\ USDA/APHIS Wildlife Services National Wildlife Research Center
}

Follow this and additional works at: https://digitalcommons.unl.edu/icwdm_usdanwrc

Part of the Natural Resources and Conservation Commons, Natural Resources Management and

Policy Commons, Other Environmental Sciences Commons, Other Veterinary Medicine Commons,

Population Biology Commons, Terrestrial and Aquatic Ecology Commons, Veterinary Infectious Diseases

Commons, Veterinary Microbiology and Immunobiology Commons, Veterinary Preventive Medicine,

Epidemiology, and Public Health Commons, and the Zoology Commons

Witmer, Gary; Snow, Nathan P.; and Moulton, Rachael S., "Time allocation to resources by three species of rats (Rattus spp.) in a radial arm maze" (2020). USDA National Wildlife Research Center - Staff Publications. 2319.

https://digitalcommons.unl.edu/icwdm_usdanwrc/2319

This Article is brought to you for free and open access by the U.S. Department of Agriculture: Animal and Plant Health Inspection Service at DigitalCommons@University of Nebraska - Lincoln. It has been accepted for inclusion in USDA National Wildlife Research Center - Staff Publications by an authorized administrator of DigitalCommons@University of Nebraska - Lincoln. 


\title{
Time allocation to resources by three species of rats (Rattus spp.) in a radial arm maze
}

\author{
Gary W. Witmer (iD) A,B, Nathan P. Snow ${ }^{\mathrm{A}}$ and Rachael S. Moulton ${ }^{\mathrm{A}}$ \\ A USDA/APHIS Wildlife Services National Wildlife Research Center, 4101 Laporte Avenue, Fort Collins, \\ CO 80521-2154, USA. \\ ${ }^{B}$ Corresponding author. Email: gary.w.witmer@usda.gov
}

\begin{abstract}
Context. Introduced rats (Rattus spp.) can pose a serious threat to native flora and fauna, especially on islands where most species have evolved in the absence of terrestrial predators. Effective detection and eradication methods for introduced rats are essential to the maintenance of insular ecosystem integrity. Thus, it is important to better understand the behaviour of rats when they first arrive in a new setting.

Aims. To determine whether rats would find some novel stimuli to be significantly more attractive than other novel stimuli.

Methods. An eight-arm radial maze was used to study the behaviour of three species of Rattus finding themselves in a novel environment with various familiar and unfamiliar stimuli.

Key results. Although there were some differences in responses by species and by sex, most rats sought out and spent considerable time in the den box, suggesting an immediate need for security when in an unfamiliar setting. Rats also sought out faeces of conspecifics, suggesting the need for social contact or reproduction. The rats, which had not been food deprived, did not seem interested in food sources, although there was some attraction to the water source.

Implications. The management implications of the present study's results are two-fold. First, appears that detection of newly arriving rats on islands would be aided by strategic placement of den boxes that are highly acceptable to rats. Managers could then inspect the den boxes periodically (or use a remote sensing system) for evidence of rat presence. Second, the den boxes could be scented with the faeces of other rats to further attract invading rats to the den boxes. This protocol might also hold the rats near the invasion site for a longer period of time before they begin seeking other shelter, food sources or mates. These protocols could give managers increased opportunities to detect any newly invading rats, and potentially increase the available time to deploy a rapid response to the invasion, before the animals begin to widely disperse. Of course, the rats will ultimately seek a source of palatable food, so placing durable, yet palatable, rodenticide bait in the den boxes might further decrease the probability of the invaders establishing a self-sustaining population.
\end{abstract}

Additional keywords: attractants, invasive species, novel environment.

Received 20 October 2018, accepted 17 August 2019, published online 18 December 2019

\section{Introduction}

Introduced rats (Rattus spp.) can pose a serious threat to native flora and fauna species, especially on islands where most species have evolved in the absence of terrestrial predators (Brown 1997; Witmer and Shiels 2018). Once rats become established in island ecosystems, they often multiply quickly because they usually have few, if any, predators. Also, the omnivorous foraging habits of rats frequently result in the decline or extinction of many island species (Moors and Atkinson 1984).

Eradication efforts to remove rats most often include systematic and intensive trapping and/or blanket application of toxicant rodenticide baits. Methods used to eradicate rats at high densities may not be appropriate for intercepting rats at low densities (Russell et al. 2005). Dense grids of bait stations may not be effective because of rats' neophobia (Russell et al. 2005), and bait stations may be inappropriately designed for rats (Spurr et al. 2006; Spurr et al. 2007). Additionally, invading rats typically roam widely (Russell 2007), so entry rates, rather than encounter rates of bait stations, are likely more important. A better understanding of how rats behave, and of their needs when they are exposed to an unfamiliar ecosystem, would allow managers to more strategically plan detection and eradication efforts. This information could be especially useful immediately after a rat invasion takes place when only a few individual animals are present on the island, so that managers could use more focused and (hopefully) more efficient and effective detection and eradication methods. The present study closely examined what rats investigate first and investigate more frequently in unfamiliar environments: the odour of conspecifics (i.e. dens or burrows previously used by rats); or an attractant/toxicant bait commonly 
used in permanent bait stations or in den sites as a response to rat invasions.

Little is known about the initial dispersal of a species when individuals arrive at a new setting such as an island (Puth and Post 2005). Russell (2007) found that the rats behaved differently in new unfamiliar settings and at low densities from how they would otherwise, when he released male Norway rats on a small island in New Zealand. He found that rats remained near their release site for a few days, but changed den sites frequently. By the end of a week, they had begun to move and explore extensively, moving $1 \mathrm{~km}$ or more over the course of a night. Knowing what rodents do and what they seek upon invading an island is important for proper development of detection and monitoring programs as well as eradication or long-term management programs (Towns and Broome 2003; Russell et al. 2005; Clapperton 2006).

We do know that rats are very adaptable in terms of their feeding and reproductive strategies and in their social systems, and show a high level of behavioural plasticity (Meehan 1984; Timm and Salmon 1988; Macdonald et al. 1999). These characteristics have allowed them to become established worldwide, both in uninhabited areas and in areas densely populated by humans (Meehan 1984; Howald et al. 2007). Additionally, one of their adaptations that helps ensure survival is the neophobia exhibited by some species of Rattus, and in particular, $R$. norvegicus and $R$. rattus (Meehan 1984; Barnett 1988; Brigham and Sibly 1999). This occurs when rats avoid new objects or foods placed in their territories or along their normal travel routes (Brigham and Sibly 1999). However, rats will explore new areas and commit to memory the objects, food sources, travel routes and safe harbourages in their territories (Barnett and Cowan 1976; Timm and Salmon 1988; Mastrangelo et al. 2009). This, along with their keen senses of smell, taste and feel, allow them to quickly move about in the darkness while evading predation or other threats. Exploratory behaviour can involve intrinsic and extrinsic factors; furthermore, exploratory drives and behaviour are complex and only partially understood (Birke and Archer 1983; Russell 1983; Barnett 1988; Hughes 1997). Some of the main drives that motivate and direct the activities of rats are: (1) maintenance of homeostasis; (2) the need for food and water; (3) the need for a secure place in which to rest, feed, avoid inclement weather, avoid predation and raise their young; and (4) the need to reproduce (Meehan 1984).

Radial arm mazes have typically been used in operant conditioning studies to test the spatial memory abilities of laboratory animals (Barnett et al. 1978; Van Haaren et al. 1987; Ilersich et al. 1988). The maze usually consists of between six and 12 arms, all radiating from a single starting point. These mazes can also be used to test for preferences among different olfactory cues or other attractants. Different cues or attractants are placed in different arms of the maze, then a rat is placed at the starting point and allowed to make a selection. By noting which attractant the rat visits first and by comparing visitation frequencies and the duration of visits, inferences can be made about the preferences of the rat. In our case, placing different activities and different basic needs of rats (i.e. food, water, shelter) at the ends of the different arms of the maze, and by recording how the rat allocates its time among these resources, we can draw conclusions on the priorities of a rat. If we better understand which needs rats first look to fulfil when they invade a new environment, we can then extrapolate this hierarchy of needs to wild rats invading a new ecosystem. This information will help develop quicker management responses to rat invasions by more quickly focusing on those resources that rats are most actively seeking out in the environment. The objective of the present study was to quantify the responses of three species of rats (Rattus spp.) to differing odours or stimuli in an unfamiliar environment using a radial arm maze. We hypothesised that rats would find some novel stimuli to be significantly more attractive than other novel stimuli.

\section{Methods}

In total, 30 rats (15 male and 15 female) of each of three species of rats, Norway rats (Rattus norvegicus), black rats ( $R$. rattus) and Polynesian rats ( $R$. exulans), were used in the present study. Norway rats were collected from wild populations in the Fort Collins, Colorado area. Black rats were from populations in the Phoenix, Arizona area. Polynesian rats were from the Hilo, Hawaii area. Animals were captured using live cage traps and transported to the USDA National Wildlife Research Center, Fort Collins, Colorado, and were quarantined at 4 weeks before the initiation of the study. The rats were maintained in individual shoebox-size plastic cages. They were fed commercial rodent chow and apple slices, and had access to water ad libitum and a den box.

The radial arm maze (MED-RAM-1R, MED Associates, Inc., Georgia, VT) consisted of eight $(45 \times 9 \times 17 \mathrm{~cm})$ arms fitted with different attachments at the end of each arm. The eight arms were centrally connected by a hub chamber. The maze attachments at the ends of each arm were randomly assigned, but were always maintained in the same order for all trials to reduce confounding, lingering odour effects. Six of the eight arms had 'head' boxes at their end, each containing one of the following odour-emitting substances: rodent chow pellets (their normal food); a fresh vegetable (Brussels sprouts); anticoagulant (diphacinone) rodenticide pellets (known to be palatable to rodents); female rat faeces; male rat faeces; or an empty box. The rat could closely approach the odour in the box at the end of each arm, but could not actually handle or access the materials because of a wire mesh placed over the odour item. A seventh arm contained a water bottle head box from which the rat could drink. The final arm was attached to a $30 \times 24 \times 21-\mathrm{cm}$ den box that the rat could enter. The floor of the den box was covered by a piece of burlap fibre and a $15-\mathrm{cm}$ piece of halved PVC pipe (15 cm diameter) for cover; these materials were replaced with clean materials after each trial.

The maze was equipped with infrared sensors able to detect when a rat entered or left an arm of the maze, and when it stuck its head in a box at the end of an arm. This information was then sent to a computer where it was organised and analysed using software programs supplied by the manufacturer. The software also recorded the order of entry into the arms and how many seconds the rat spent in each arm of the maze. This allowed us to determine which stimuli rats immediately focused on by examining what they responded most frequently to, and the stimuli near which they spent more of their time.

Under dark or red-light conditions (because rats are primarily nocturnal), an individual rat was placed in the centre hub of the radial arm maze for $15 \mathrm{~s}$ before all eight doors to the arms opened. 
The rat then had 15 min to explore the maze and its various odours before the doors to the hub closed, ending the session for that rat. The rat was then returned to its holding cage. The maze was opened completely and wiped down with an odourless, environmentally friendly cleanser. The maze was allowed to air dry before being reassembled for the next rat. All rats were euthanised at the end of the study using a $\mathrm{CO}_{2}$ chamber.

The dataset was analysed using least-squares to fit generalised linear regression models with the SAS procedure PROC GLM (SAS ver. 9.1, SAS Institute, Cary, NC, USA). Specifically, we examined how rat species, rat sex, treatment (the odour or stimuli in each arm of the maze) and all two-way interactions of those variables influenced three dependent variables of: (1) the number of head entries; (2) the number of arm entries; and (3) the total time spent in each arm or the hub of the radial arm maze. We considered effects to be significant at the level of $\alpha=0.05$, and made inferences using the Type III Sum of Squares. We also evaluated contrasts for differences in the

Table 1. Type III tests of fixed effects for the statistical analysis of the head entries into a radial arm maze for three species of rats (black, Norway and Polynesian) in 15-min trials

\begin{tabular}{lrrr}
\hline Effect & d.f. & \multicolumn{1}{c}{$F$} & \multicolumn{1}{c}{$P$} \\
\hline Species & 2 & 7.44 & 0.0010 \\
Treatment & 7 & 28.96 & $<0.0001$ \\
Treatment $\times$ species & 14 & 4.10 & $<0.0001$ \\
Sex & 1 & 0.11 & 0.7460 \\
Sex $\times$ species & 2 & 0.56 & 0.5700 \\
Treatment $\times$ sex & 7 & 2.58 & 0.0150 \\
Treatment $\times$ sex $\times$ species & 14 & 0.24 & 0.9980 \\
\hline
\end{tabular}

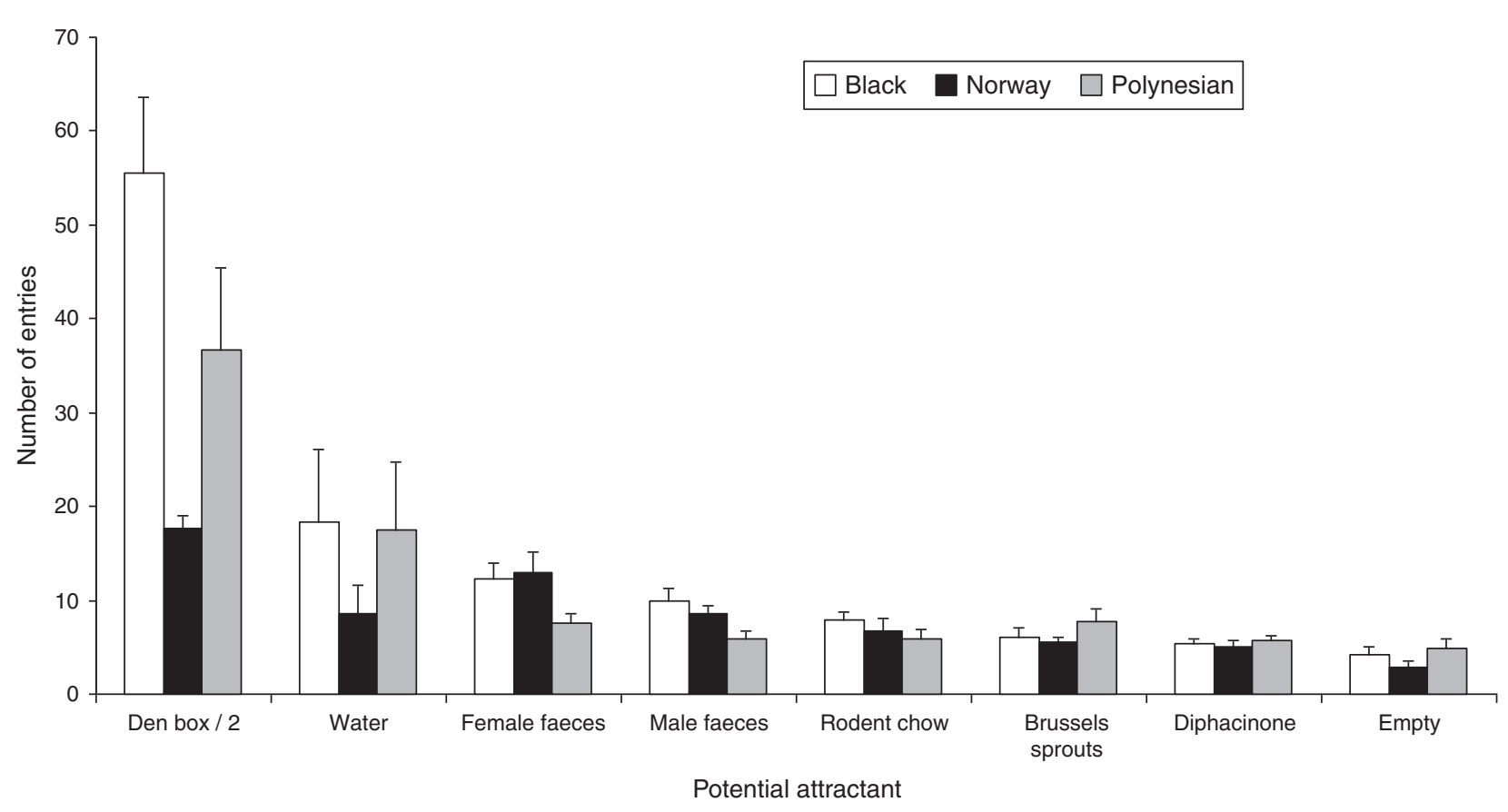

Fig. 1. Mean number of head entries by species and attractant type in 15-min trials in a radial arm maze. Vertical lines are the standard errors. dependent variables among all treatment types, for each species and each sex.

\section{Results}

We observed that all species of rats could put their entire body into the den box, but could only insert their head into the head boxes at the end of each of the other maze arms. Therefore, the sensors at the entrance of the den box counted an 'entry' occasion every time the rat entered and exited the box. As a conservative estimate, we divided all entry occasions into the den box by two for every individual, to make the den box entries comparable to the head box entries. We also excluded one male Polynesian rat from the dataset because it did not move from the den box once the trial began, and was thus an extreme outlier data point.

\section{Head entries}

Entries into all head boxes were significantly different by species and by treatment. We also found that the interactions of treatment $\times$ species and treatment $\times$ sex influenced the total head entries recorded (Table 1).

The overall mean number of head entries for each head box differed among black rats $\left(F_{7,72}=17.76, P<0.0001\right)$, Norway rats $\left(F_{7,72}=9.81, P<0.0001\right)$ and Polynesian rats $\left(F_{7,64}=7.10\right.$, $P<0.0001)$. Compared with all other head entry treatment means, entries into the den box occurred more often for black rats $\left(F_{1,72}=115.44, P<0.0001\right)$, Norway rats $\left(F_{1,72}=41.69\right.$, $P<0.0001)$ and Polynesian rats $\left(F_{1,64}=42.84, P<0.0001\right)$. Black rats entered den boxes the most, followed by Polynesian rats, and then Norway rats (Fig. 1). Norway rats also entered the head box with female faeces more often, compared with all other head entry treatment means $\left(F_{1,70}=9.80, P=0.003\right.$; Fig. 1$)$. 


\section{Arm entries}

Entries into all arms from the hub of the maze were significantly different by treatment. We also found that the interactions of treatment $\times$ species and sex $\times$ species influenced the total arm entries recorded (Table 2).

The overall number of mean radial arm entries for each arm differed between black rats $\left(F_{7,72}=26.12, P<0.0001\right)$ and Norway rats $\left(F_{7,72}=16.97, P<0.0001 ;\right.$ Fig. 2$)$. However, there was no difference in the mean number of radial arm entries for the Polynesian rats $\left(F_{7,64}=1.99, P=0.071\right.$; Fig. 2$)$. Black rats entered radial arms with den boxes the most, followed closely by those with female faeces (Fig. 2). Norway rats entered radial arms with female faeces the most, followed by those with male faeces (Fig. 2). Although Polynesian rats did not show a significant difference in radial arms entered, they tended to enter food arms (Brussels sprouts and rodent chow) more so than other arms (Fig. 2).

Table 2. Type III tests of fixed effects for the statistical analysis of arm entries into a radial arm maze for three species of rats (black, Norway and Polynesian) in 15-min trials

\begin{tabular}{lrrr}
\hline Effect & d.f. & \multicolumn{1}{c}{$F$} & \multicolumn{1}{c}{$P$} \\
\hline Species & 2 & 1.34 & 0.2650 \\
Treatment & 7 & 27.50 & $<0.0001$ \\
Treatment $\times$ species & 14 & 2.70 & 0.0010 \\
Sex & 1 & 2.13 & 0.1460 \\
Sex $\times$ species & 2 & 6.97 & 0.0010 \\
Treatment $\times$ sex & 7 & 0.88 & 0.5260 \\
Treatment $\times$ sex $\times$ species & 14 & 0.86 & 0.6030 \\
\hline
\end{tabular}

\section{Time in arms}

Times (in minutes) spent in each arm of the maze were significantly different by treatment. We also found that the interaction of treatment $\times$ species influenced the total amount of time spent in each arm (Table 3).

The overall mean amount of time spent in each of the radial arms differed among black rats $\left(F_{8,81}=104.36, P<0.0001\right)$, Norway rats $\left(F_{8,81}=31.84, P<0.0001\right)$ and Polynesian rats $\left(F_{8,72}=27.08, P<0.0001\right.$; Fig. 3$)$. All three species of rats spent the most time in the den box or the maze's central hub (Fig. 3).

\section{Differences between sexes within a species \\ Black rats}

The number of entries into the head portion of the den box, compared with all other head entries, was greater for males (Fig. 4). Males entered the male faeces, rodent chow, Brussels sprouts, diphacinone and empty treatment the least. Females

Table 3. Type III tests of fixed effects for the statistical analysis of the time (in minutes) spent in each arm of a radial arm maze for three species of rats (black, Norway and Polynesian) in 15-min trials

\begin{tabular}{lrrr}
\hline Effect & d.f. & \multicolumn{1}{c}{$F$} & \multicolumn{1}{c}{$P$} \\
\hline Species & 2 & 0.00 & 1.0000 \\
Treatment & 8 & 125.43 & $<0.0001$ \\
Treatment $\times$ species & 16 & 5.71 & $<0.0001$ \\
Sex & 1 & 0.00 & 0.9970 \\
Sex $\times$ species & 2 & 0.00 & 1.0000 \\
Treatment $\times$ sex & 8 & 1.34 & 0.2250 \\
Treatment $\times$ sex $\times$ species & 16 & 1.24 & 0.2430 \\
\hline
\end{tabular}

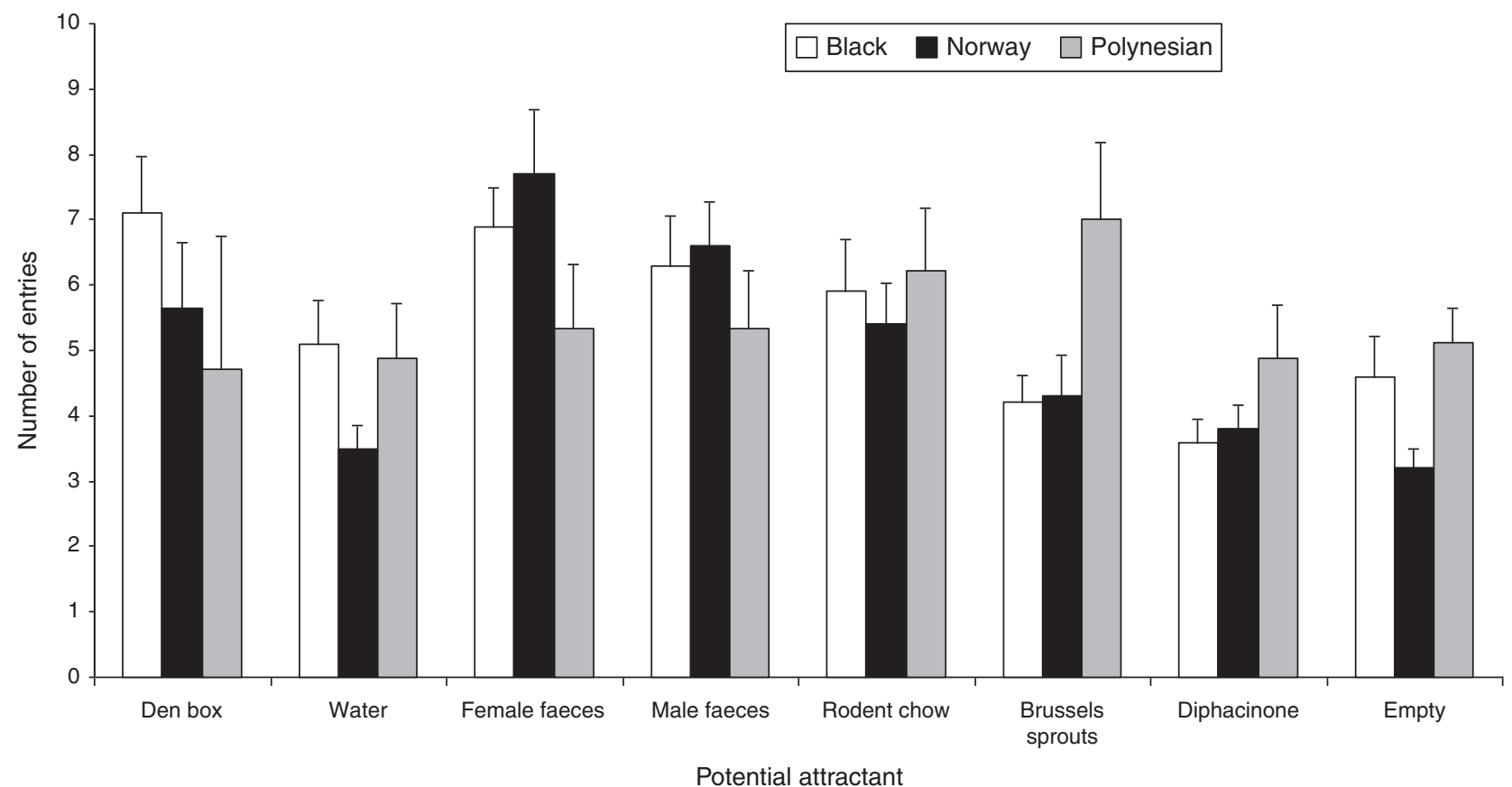

Fig. 2. Mean number of arm entries by species and attractant type in a 15-min trial in a radial arm maze. Vertical lines are the standard errors. 
entered the den box most often, and all other treatment types the same amount.

\section{Norway rats}

The number of entries into the head portion of the den box, water and female faeces, compared with all other head entries, was greater for males (Fig. 5). Males visited the Brussels sprouts, diphacinone and the empty treatments the least. Females entered the den box and female faeces more often than all other treatments. Females visited the water, diphacinone and the empty treatments the least.

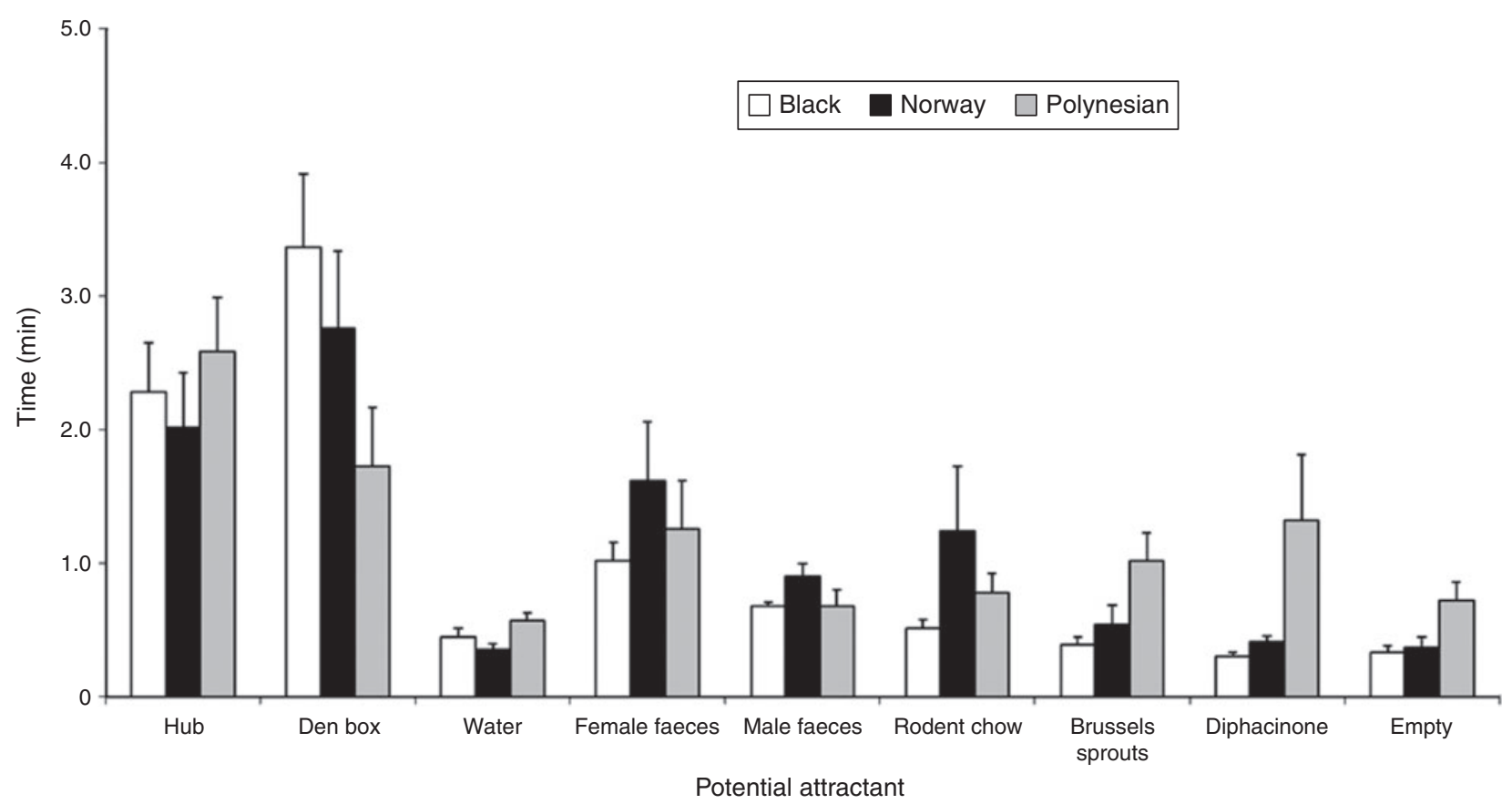

Fig. 3. Mean amount of time (in minutes) by species and attractant arm in a 15-min trial in a radial arm maze. Vertical lines are the standard errors.

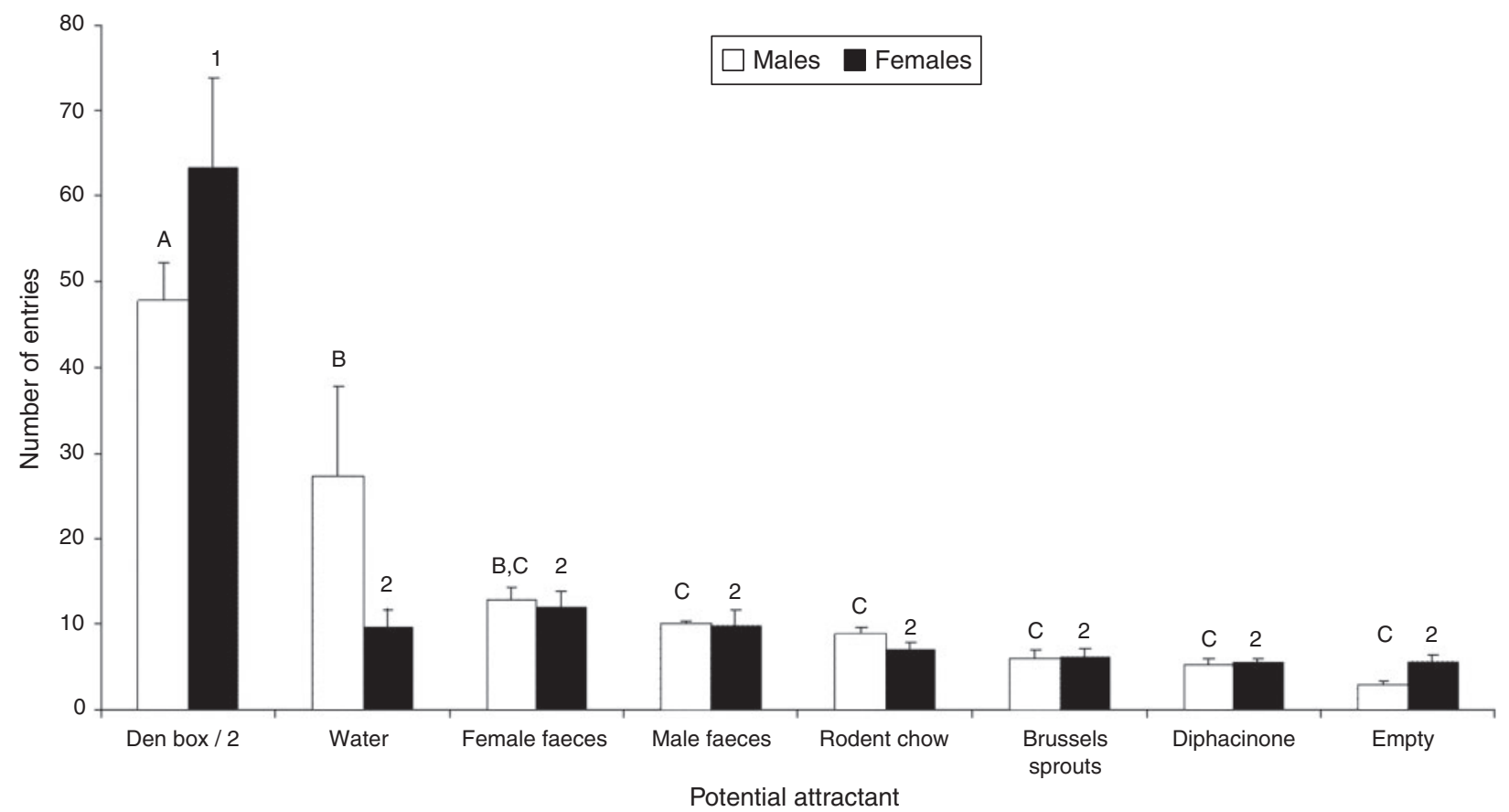

Fig. 4. Mean amount of head entries for black rats by sex and attractant in a 15-min trial in a radial arm maze. Vertical lines are the standard errors. Means with the same letters (number for females) are not significantly different at the level of $\alpha=0.05$. 


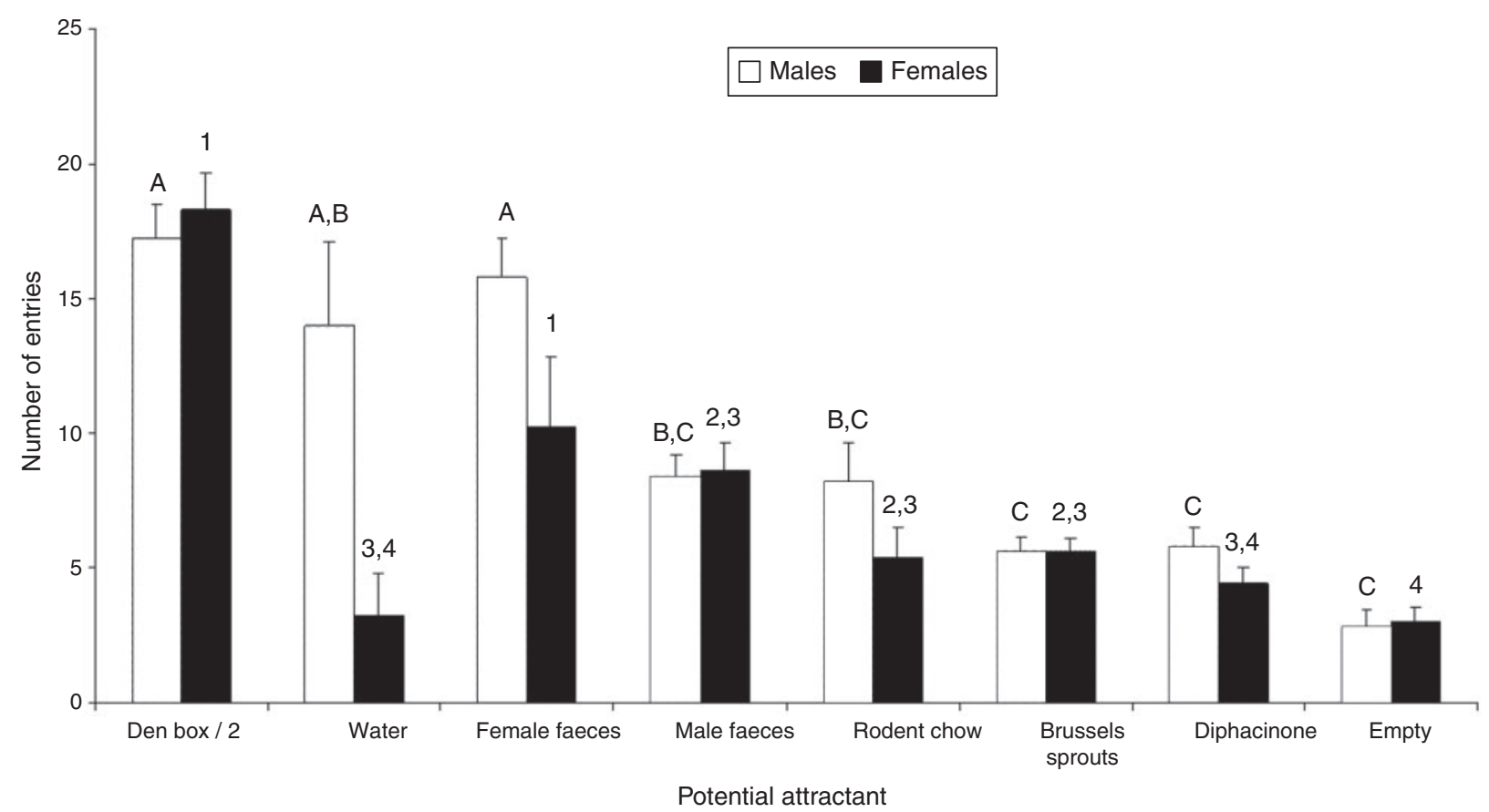

Fig. 5. Mean amount of head entries for Norway rats by sex and attractant in a 15-min trial in a radial arm maze. Vertical lines are the standard errors. Means with the same letters (number for females) are not significantly different at the level of $\alpha=0.05$.

\section{Polynesian rats}

The number of entries into the head portion of the den box and water treatment was greater for males (Fig. 6). Males entered the female faeces, male faeces, rodent chow, diphacinone and empty treatments the least. Females entered the den box most often, and all other treatments the same amount.

\section{Discussion}

Much recent rodent research has focused on identifying food items and/or odours that will increase the probability of detecting rodents (track stations, remote cameras), of capturing rodents (live traps, kill traps) or of poisoning rodents (bait stations, bait grids). For example, in New Zealand, Jackson et al. (2016) identified several materials that increased food consumption by Norway rats over the 'standard' of peanut butter. In China, Hegab et al. (2014) found that Norway rats fed on corn more so than several other food types. They also found that rats preferred foods with high carbohydrate content and that rats were less neophobic to foods with high sugar content. In Germany, Hansen et al. $(2016,2017)$ found that some rodents (house mice (Mus musculus) and voles (Microtis arvalis)) were attracted to some plant secondary metabolites, whereas other plant secondary metabolites had a repellent effect. In the United Kingdom, Inglis et al. (1996) found wide variation in Norway rat responses to new foods, but also to new food containers. They also found that neophobia to new food containers was much stronger than neophobia to new foods. In Canada, Takács et al. (2018) found that house mice, black rats and Norway rats preferred a new food bait over traditional food baits, presumably because of the attractiveness of the new food attractant blends. In the United States, Witmer et al. (2014) found that house mice in a novel environment sought out shelter in a den box over food odours presented. However, among the various food odours presented, mice preferred bacon grease, peanut butter and cheese. Also in the United States, Witmer et al. (2010) found that invasive Gambian giant pouched rats (Cricetomys gambianus) preferred conspecific odours over food odours. However, among the various food odours presented, the rats preferred peanut butter, anise, ginger and fatty acid scent.

Unlike many of the studies mentioned above, our study focused on more than just food odours. In addition to food odours, we included den boxes, water and conspecific odours in a radial arm maze. While rat behaviour and activities in mazes has been studied over many years and by many researchers, we did some things differently. We used wild rats rather than laboratory strains of rats because there can be marked differences in behaviours and activities (Boice 1971; Mitchell 1976; Shepherd and Inglis 1987; Barnett 1988; Berdoy and Macdonald 1991). For example, wild Norway rats tend to be much more neophobic and aggressive than laboratory strains (Brigham and Sibly 1999), and maintain their wild behaviours for a considerable length of time after being brought into captivity (Priyambodo and Pelz 2003). We also did not allow the rats to acclimate to the maze, which is commonly done in rat behaviour and learning trials (e.g. Barnett et al. 1978; Van Haaren et al. 1987; Mastrangelo et al. 2009), before we began our trials because we wanted to record their initial responses to a very unfamiliar environment. Presumably, this would better reflect the initial behaviours of rats when first arriving on an island.

Rats, regardless of species, entered into den boxes more than any other boxes. This may have simulated cover and a more secure environment for the rats. Thus, locating a safe covered area might be a primary need of rats newly arriving on an island. 


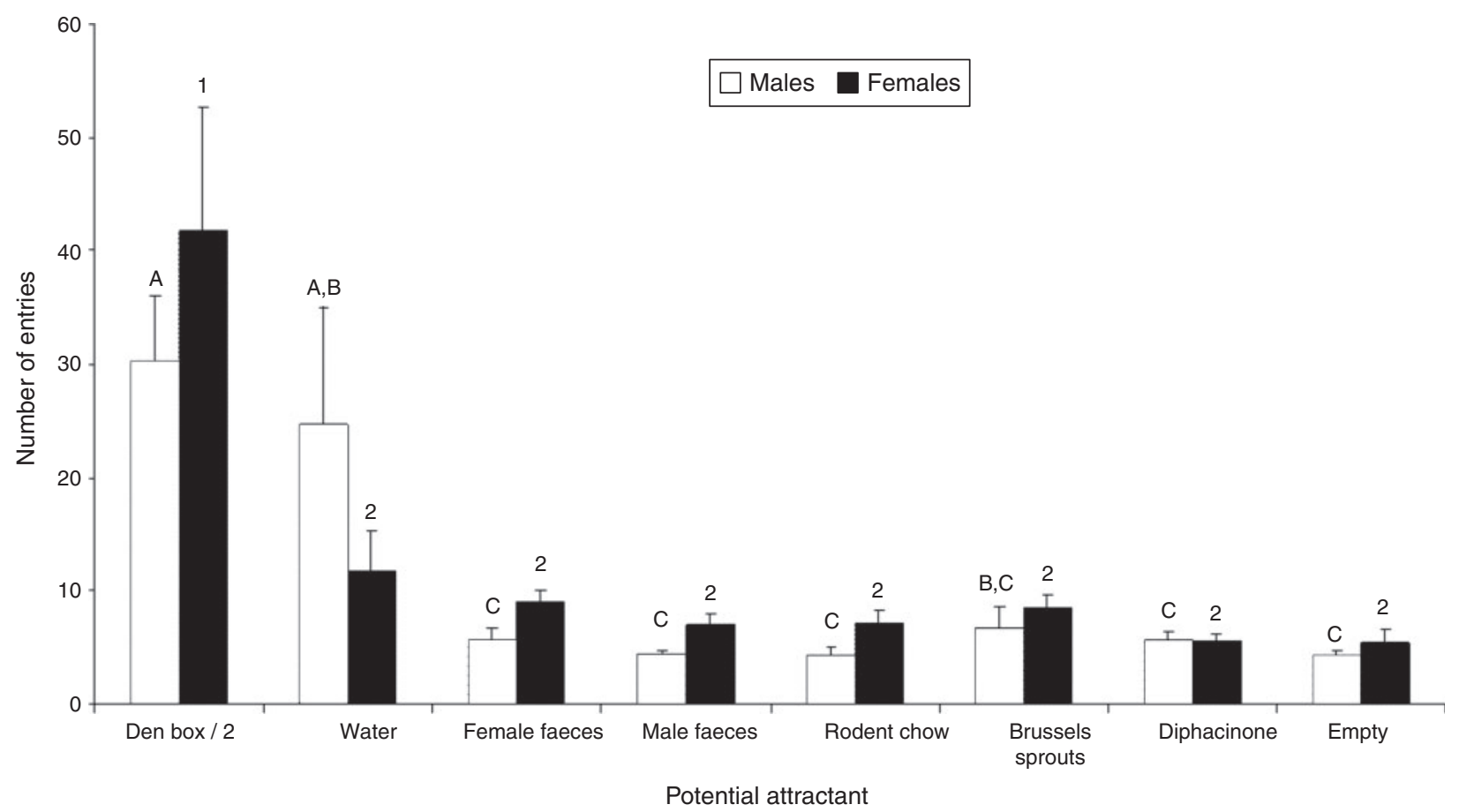

Fig. 6. Mean amount of head entries for Polynesian rats by sex and attractant in a 15-min trial in a radial arm maze. Vertical lines are the standard errors. Means with the same letters (number for females) are not significantly different at the level of $\alpha=0.05$.

This would seem to be consistent with the finding of Russell (2007), whose radio-collared Norway rats moved very little for the first several days after being placed on an island. The den boxes may have also added an element of familiarity for the rats because these rooms contained a curved, semi-circle of PVC pipe that rats can get under and that sat on a piece of burlap - the same materials used in their individual holding cages as shelters. The second highest number of head entries for black and Polynesian rats were into the water bottle head box. We could not determine if the rats were drinking measurable amounts of water because we did not notice any reduction in water levels of the water bottles at the end of any of the 15-min maze exposure periods. We do know that the various Rattus species have a daily requirement for water (Meehan 1984). On the other hand, our rats had access to water ad libitum in each of the holding cages, so we know they were not dehydrated at the time of the maze sessions. Importantly, the water bottle in a head box was the only head box in which the rat could perform an activity (drinking), because wire mesh prevented rats from making direct contact with the stimuli material in each of the other head boxes (a food type, rat faeces or an empty box). The second-most visited head box by Norway rats was the female faeces head box. We do not know if this was a reflection of a need to locate conspecifics or to reproduce. However, reproduction is likely not an immediate need when a rat encounters an unfamiliar environment. Conversely, reproduction is known to be a relatively strong need amongst Norway rats and our rats had been confined to individual cages for a month before the maze trials were conducted. Interestingly, the rats made relatively few head entries in the food boxes. Likely, the rats were not hungry because they were not fasted before the trial. Fasting is commonly done to stimulate activity and learning in mazes, with food being used as a reward (Van Haaren et al. 1987; Ilersich et al. 1988).

The number of entries into the various arms of the maze varied by species. Black rats entered arms with a den box at the end of the arms the most, followed closely by arms with female faeces in the box at the end of the arms. Norway rats entered maze arms with female faeces in the box at the end of the arms the most, followed by arms with male faeces in the box at the end of the arms. This seems consistent with the number of box entries discussed in the previous paragraph. Interestingly, Polynesian rats tended to enter arms of the maze with boxes containing foods at the end of the arms. It may be important to note that all arms of the maze were visited relatively often by rats of all species; this may be a reflection of an innate exploratory behaviour that is important in an unfamiliar environment where the rats have not yet located and memorised consistent locations of food and shelter (Barnett 1988; Hughes 1997).

It is important to reiterate the short time frame (15 min) used in this radial-arm maze study. This was done intentionally to better discern how rats would immediately respond to a novel environment. However, it is important to realise that their responses and preferences could change substantially given more time in the novel environment. For example, they may seek a safe, secure location initially, but if a palatable food source is not nearby, they would have to seek one out. Also, if no other rats show up near their secure location for a while, the rat may seek out companions and/or mates at other locations. Repeating the present study using a longer time frame (an hour or more) might help discern these potential changes over time.

In terms of where the rats spent the most time, den boxes again ranked high, along with the central hub. As mentioned 
previously, the den boxes probably provided a sense of security for the rats. Interestingly, all three species spent considerable time in the central hub. This may have resulted from the rats' insecurity in the maze and not wanting to move about very much in the unfamiliar environment, other than to the den box, which provided a safe and somewhat familiar refuge. Also, the size of the maze allowed the rats to explore and perhaps memorise all parts of the maze in a relatively short time. Had we allowed the rats to feed at the end of some arms, different results may have been observed. For example, Barnett et al. (1978) found that rats in a maze tended to visit areas with preferred foods for a lengthy feeding bout after a period of resting at a different location. They would then briefly visit other sites with less preferred foods to do a bit of food sampling. Wallace (2003) reported that if Norway rats had been somewhat food deprived, they tended to go to a food source and feed initially, followed by extended bouts of food retrieval (or hoarding). Researchers have found that rats will periodically visit all parts of a maze, including empty arms (Barnett et al. 1978). With free-ranging rats, this is believed to be an important part of patrolling their territory as well as being an exploratory behaviour that allows for the discovery of new resources and, in particular, new food sources (Barnett 1988; Timm and Salmon 1988). This would be especially important in unstable or seasonal environments, such as islands where food availability and nutritional content changes at least seasonally, and where unexpected sources of food can show up at any time (such as biological materials washing up on shores) (Russell 1983; Witmer et al. 2006).

There were relatively few significant differences in head entries by sex. For black rats, females entered the den box somewhat more often than males, and males made more head entries into the water bottle box than females. The most noticeable difference in head entries by sex of Norway rats was that males tended to make more head entries in water bottle boxes and female faeces boxes than females. Among the Polynesian rats, females tended to enter the den box more often than males, and males made more head entries in water bottle boxes than females. Therefore, depending on the species and sex of any newly invading rat(s), different stimuli may draw the rats near, and using different monitoring techniques or a den box with multiple attractants might be useful for detecting rats.

The present study of wild rat responses to being placed in an unfamiliar eight-arm radial maze provided some insight into how rats might initially respond to arriving on an unfamiliar island. The number of entries and the time spent in den boxes suggest that an important need for rats is to seek out a secure place that provides safety from predation or other threats when in an unfamiliar environment. Rodents are subject to predation by a variety of species and often adapt their activities as a result (Birke and Archer 1983; Macdonald et al. 1999; Ylonen and Brown 2007). The rats in the present study visited all parts of the maze (arms and head boxes), suggesting the importance of exploratory behaviour to ultimately locate food sources, and conspecifics or potential mates, in an unfamiliar environment. This latter need is also suggested by the substantial number of visits to the head boxes containing rat faeces. We do caution, however, that the relatively few visits to, and time spent in the maze arms of, food boxes might have been different if the rats had been food deprived or had been allowed to feed on the materials in the food item head boxes. Additional trials with fasted rats would help provide an answer to that situation. Additionally, we caution that the results with captive, albeit wild, animals in a very unnatural environment (cages, mazes, animal pens) do not necessarily respond in the same ways that free-ranging animals of the same population would respond (e.g. Russell 1983; Witmer et al. 2008). Finally, it is important to realise that all rats of a population cannot be expected to respond in the same way to a stimulus or a novel situation because rats exhibit considerable variation in individual behaviour and responses (Barnett and Spencer 1951; Mitchell 1976; Shepherd and Inglis 1987).

The management implications of our study results are twofold, although further investigation of these preliminary findings are warranted. First, it would appear that to detect newly arriving rats on an island, managers might benefit from placing den boxes (that are highly acceptable to rats) at locations where the invasion is most likely to occur. Second, the den boxes should perhaps be scented with the faeces of other rats. These actions might hold the rats near the invasion site for a longer period of time before they begin seeking other shelter, food sources or mates. Russell et al. (2008) also suggested that invading rats may be more readily detected using multiple devices and attractants. This strategy should give managers a better chance to detect the newly arrived invaders and to deploy a rapid response to the invasion before the animals begin to widely disperse. Of course, the rats will ultimately seek a source of palatable food, so placing durable, palatable rodenticide bait in the den boxes might further decrease the probability of the invaders establishing a self-sustaining population.

\section{Conflicts of interest}

The authors declare no conflicts of interest.

\section{Acknowledgements}

We appreciate the assistance of Susan Jojola in the early stages of the present study. We also thank the landowners who allowed us to trap wild rats on their properties. The present study was funded by the USDA National Wildlife Research Center, and was conducted under the NWRC IACUC-approved study protocol QA-1456. Mention of a commercial product or company does not represent an endorsement by the USA government.

\section{References}

Barnett, S. (1988). Exploring, sampling, neophobia, and feeding. In 'Rodent Pest Management'. (Ed. I. Prakash.) pp. 295-320. (CRC Press: Boca Raton, FL.)

Barnett, S., and Cowan, P. (1976). Activity, exploration, curiosity and fear: an ethological study. Interdisciplinary Science Reviews 1, 43-62. doi:10. 1179/030801876789768534

Barnett, S., and Spencer, M. (1951). Feeding, social behaviour and interspecific competition in wild rats. Behaviour 3, 229-242.

Barnett, S., Dickson, R., Marples, T., and Radha, E. (1978). Sequences of feeding, sampling, and exploration by wild and laboratory rats. Behavioural Processes 3, 29-43. doi:10.1016/0376-6357(78)90028-1

Berdoy, M., and Macdonald, D. (1991). Factors affecting feeding in wild rats. Acta Oecologica 12, 261-279.

Birke, L., and Archer, J. (1983). Some issues and problems in the study of animal exploration. In 'Exploration in Animals and Humans'. (Eds J. Archer, and L. Birke.) pp. 1-21. (Van Nostrand Reinhold: Berkshire, UK.) 
Boice, R. (1971). Laboratizing the wild rat (Rattus norvegicus). Behavior Research Methods and Instrumentation 3, 177-182. doi:10.3758/ BF03208127

Brigham, A., and Sibly, R. (1999). A review of the phenomenon of neophobia. In 'Advances in Vertebrate Pest Management'. (Eds D. Cowan, and C. Feare.) pp. 67-84. (Filander Verlag: Firth, Germany.)

Brown, K. P. (1997). Predation at nests of two New Zealand endemic passerines; implications for bird community restoration. Pacific Conservation Biology 3, 91-98. doi:10.1071/PC970091

Clapperton, B. (2006). A review of the current knowledge of rodent behavior in relation to control devices. Science for Conservation 263. New Zealand Department of Conservation, Wellington, New Zealand.

Hansen, S., Solter, C., and Jacob, J. (2016). Effect of plant secondary metabolites on feeding behavior of microtine and arvicoline rodent species. Journal of Pest Science 89, 955-963. doi:10.1007/s10340015-0723-6

Hansen, S., Stolter, C., Imholt, C., and Jacob, J. (2017). Like or dislike: responses of rodents to the odor of plant secondary metabolites. Integrative Zoology 12, 428-436. doi:10.1111/1749-4877.12245

Hegab, I., Pan, H., Junyan, D., Wang, A., Yin, B., Yang, S., and Wei, W. (2014). Effects of physical attributes and chemical composition of novel foods on food selection by Norway rats (Rattus norvegicus). Journal of Pest Science 87, 99-106. doi:10.1007/s10340-013-0511-0

Howald, G., Donlan, C., Galvan, J., Russell, J., Parkes, J., Samaniego, A., Wand, Y., Veitch, D., Genovesi, P., Pascal, M., Saunders, A., and Tershy, B. (2007). Invasive rodent eradication on islands. Conservation Biology 21, 1258-1268. doi:10.1111/j.1523-1739.2007.00755.x

Hughes, R. (1997). Intrinsic exploration in animals: motives and measurement. Behavioural Processes 41, 213-226. doi:10.1016/S03766357(97)00055-7

Ilersich, T., Mazmanian, D., and Roberts, W. (1988). Foraging for covered and uncovered food on a radial maze. Animal Learning \& Behavior 16, 388-394. doi:10.3758/BF03209377

Inglis, J., Shepherd, D., Smith, P., Haynes, P., Bull, D., Cowan, D., and Whitehead, D. (1996). Foraging behavior of wild rats (Rattus norvegicus) towards new food and bait containers. Applied Animal Behaviour Science 47, 175-190. doi:10.1016/0168-1591(95)00674-5

Jackson, M., Hartley, S., and Linklater, W. (2016). Better food-based baits and lures for invasive rats Rattus spp. and the brushtail possum Trichosurus vulpecula: a bioassay on wild, free-ranging animals. Journal of Pest Science 89, 479-488. doi:10.1007/s10340-015-0693-8

Macdonald, D., Mathews, F., and Berdoy, M. (1999). The behaviour and ecology of Rattus norvegicus: from opportunism to kamikaze tendencies. In 'Ecologically-Based Management of Rodent Pests'. (Eds G. Singleton, L. Hinds, H. Liers, and Z. Zhang.) Monograph No. 59, pp. 49-80. (Australian Centre for International Agricultural Research (ACIAR): Canberra.)

Mastrangelo, M., Schleich, C., and Zenuto, R. (2009). Short-term effects of an acute exposure to predatory cues on the spatial working and reference memory performance in a subterranean rodent. Animal Behaviour 77, 685-692. doi:10.1016/j.anbehav.2008.11.018

Meehan, A. (Ed.) (1984). 'Rats and Mice: Their Biology and Control.' (Rentokil Limited: East Grinstead, UK.)

Mitchell, D. (1976). Experiments in neophobia in wild and laboratory rats: a reevaluation. Journal of Comparative and Physiological Psychology 90, 190-197. doi: $10.1037 / \mathrm{h} 0077196$

Moors, P. J., and Atkinson, I. A. E. (1984). Predation on seabirds by introduced animals, and factors affecting its severity. In 'Status and Conservation of the World's Seabirds'. ICBP Technical Publication Number 2. (Eds J. P. Croxall, P. G. H. Evans, and R. W. Schrieber.) pp. 667-690. (International Council for Bird Preservation (ICBP): Cambridge, UK.)

Priyambodo, S., and Pelz, H. (2003). Studies on neophobic behavior in Norway rats from farms in Germany. In 'Rats, Mice and People: Rodent Biology and Management'. Monograph No. 96. (Eds G. Singleton, L.
Hinds, C. Krebs, and D. Spratt.) pp. 155-158. (Australian Centre for International Agricultural Research (ACIAR): Canberra.)

Puth, L., and Post, D. (2005). Studying invasion: have we missed the boat? Ecology Letters 8, 715-721. doi:10.1111/j.1461-0248.2005.00774.x

Russell, P. (1983). Psychological studies of exploration in animals: a reappraisal. In 'Exploration in Animals and Humans'. (Eds J. Archer, and L. Birke.) pp. 22-54. (Van Nostrand Reinhold: Berkshire, UK.)

Russell, J. C. (2007). Invasion ecology and genetics of Norway rats on New Zealand islands. Ph.D. Thesis, University of Auckland, Auckland.

Russell, J. C., Towns, D. R., Anderson, S. H., and Clout, M. N. (2005). Intercepting the first rat ashore. Nature 437, 1107. doi:10.1038/ $4371107 \mathrm{a}$

Russell, J., Beaven, B., MacKay, J., Towns, D., and Clout, M. (2008). Testing island biosecurity systems for invasive rats. Wildlife Research 35, 215-221. doi:10.1071/WR07032

Shepherd, D., and Inglis, I. (1987). Feeding behavior, social interactions and poison bait consumption by a family group of wild rats living in seminatural conditions. In 'Stored Products Pest'. Monograph No. 37. (Ed. T. Lawson.) pp. 97-105. (British Crop Protection Council: Croydon, UK.)

Spurr, E. B., O'Connor, C. E., Morriss, G. A., and Turner, J. (2006). Bait station preferences of Norway rats. DOC Research \& Development Series 255. Department of Conservation, Wellington, New Zealand.

Spurr, E. B., Morriss, G. A., Turner, J., O'Connor, C. E., and Fisher, P. (2007). Bait station preferences of ship rats. DOC Research \& Development Series 271. Department of Conservation, Wellington, New Zealand.

Takács, S., Musso, A., Gries, R., Rozenberg, E., Borden, J., Brodie, B., and Gries, G. (2018). New food baits for trapping house mice, black rats and brown rats. Applied Animal Behaviour Science 200, 130-135. doi:10. 1016/j.applanim.2017.11.011

Timm, R., and Salmon, T. (1988). Behavior. In 'Rodent Pest Management'. (Ed. I. Prakash.) pp. 225-235. (CRC Press: Boca Raton, FL.)

Towns, D., and Broome, K. (2003). From small Maria to massive Campbell: forty years of rat eradications from New Zealand islands. New Zealand Journal of Zoology 30, 377-398. doi:10.1080/03014223.2003.9518348

Van Haaren, F., Wouters, M., and Van de Poll, N. (1987). Absence of behavioral differences between male and female rats in different radialmaze procedures. Physiology \& Behavior 39, 409-412. doi:10.1016/ 0031-9384(87)90243-5

Wallace, R. (2003). Patterns of feeding and food pellet retrieval by Norway rats during food deprivation. Journal of Ethology 21, 111-116.

Witmer, G., and Shiels, A. (2018). Ecology, impacts, and management of invasive rodents in the United States. In 'Ecology and Management of Terrestrial Vertebrate Invasive Species in the United States'. (Eds W. Pitt, J. Beasley, and G. Witmer.) pp. 385-388. (CRC Press: Boca Raton, FL.)

Witmer, G., Burke, P., Jojola, S., and Dunlevy, P. (2006). The biology of introduced Norway rats on Kiska Island, Alaska, and an evaluation of an eradication approach. Northwest Science 80, 191-198.

Witmer, G., Burke, P., and Jojola, S. (2008). An evaluation of the effectiveness of potential Norway rat attractants. In 'Proceedings of the 23rd Vertebrate Pest Conference', 17-20 March 2008, San Diego, CA, USA. (Eds R. Timm, and M. Madon.) pp. 35-38. (University of California: Davis, CA.)

Witmer, G., Snow, N., and Burke, P. (2010). Potential attractants for detecting and removing invading Gambian giant pouched rats (Cricetomys gambianus). Pest Management Science 66, 412-416.

Witmer, G., Snow, N., and Moulton, R. (2014). Responses by wild house mice (Mus musculus) to various stimuli in a novel environment. Applied Animal Behaviour Science 159, 99-106. doi:10.1016/j.applanim.2014. 07.007

Ylonen, H., and Brown, J. (2007). Fear and the foraging, breeding, and sociality of rodents. In 'Rodent Societies: an Ecological and Evolutionary Perspective'. (Eds J. Wolff, and P. Sherman.) pp. 328-341. (University of Chicago Press: Chicago, IL.) 